\title{
Public SERVICE MEdiA AND PARTICIPATION
}

\author{
Luís António Santos \& Nelia Del Bianco
}

Especially in a European context the temptation to look at any point in the recent past as a less critical moment in the life of public service media (PSM) exists but it is not appropriate (Lowe, Goodwin \& Yamamoto, 2015, p. 11). Such a path normally leads us to less sustained considerations about possible exceptionalities of the present moment. That being said, traditionally sensitive issues such as funding, regulation, interaction with other partners in the market or the mission and supply of content are now under discussion in a particularly fragile territory - given the challenges of operating in digital contexts - and under the pressure of greater citizen participation demands.

At a time marked by visible media supply fragmentation and by permanent content flows mixing and remixing those products with content generated by the "people previously known as the audience" (Rosen, 2006) two particular questions gain relevance: for whom is and with whom is PSM to be made? (D'Haenens, Sousa \& Hultén, 2011, p. 214). In a text with a significant title, "Public Service Broadcasting in the 21st Century - what a chance for a new beginning?", Karol Jakubowicz suggests that this challenge - that of PSM's renewed self definition in relation to citizens - can be overcome with a six step strategy: removing ideological objections to its existence; providing proof that PSM is still needed; replacing the B (for Broadcast) by either a M (for Media) or a C (for Content); reaffirming and enhancing the $S$ (as service rendered to the community); decisively dealing with funding issues; and redefining the $\mathrm{P}$ (the Public has changed enormously and so have changed its expectations) (Jakubowicz, 2007, p. 30).

Organized under the project "Communication Policies, Public Broadcasting and Citizenship: Subsidies for Socio-Cultural Development in Portugal and Brazil", financed by FCT (Portugal) and Capes (Brazil), this special issue of Comunicação \& Sociedade is dedicated to the problematization of the concept of Public Media Service (PSM) and to the new challenges created by constant technological innovation, especially regarding those related to participatory communication. Perceived as an inherent obligation of public service operations, the promotion of participation needs to be equated as a prerequisite for social and cultural development and, at the same time, for the emancipation of communities.

Over the last twenty years, the possibilities for participatory communication have increased in the face of technologically induced complex dynamics and have affected the production, transmission, consumption, and sharing of media contents, especially with the popularization of mobility access. In a time of apparent ubiquity, in which networked devices integrate community routines and individuals in such a naturalized fashion, PSM needs to reinvent itself to meet the competition challenges of new and more dispersed operators offering content and online entertainment, and also to promote the provision of a distinct service, in a universal way, through different platforms. 
Rather than being willing to operate in a digital ecosystem, public media need to present themselves as accelerators of innovation in these spaces, particularly in areas such as the promotion of public debates, whether about their own existence and management or about public life in general. As Toby Mendel recalls, "public broadcasters are required to make extensive and varied use of new technologies in order to facilitate and extend the provision of services in the fulfillment of their public service remit" (Mendel, 2011, p. 21).

This edition presents a reflection on the theme from very different contexts. In Europe, the public communication system has a tradition historically attached to the idea of "public good", with obligations regarding the accessibility of citizens, the diversity of contents, and the promotion of cultural values. European public radio and television services' activities today clearly go beyond the scope of broadcasting, increasingly opening up to new formats and new channels of interaction. In Brazil, the experience of a public service based on principles of differentiation, plurality, diversity, independence, and social participation is very recent. The Brazilian public audio broadcasting service, created in 2008 based on the law that established the Brazil Communication Company, faces complex deadlocks related to a still incipient regulatory design. Indeed, the regulatory framework has been changed very recently following an intricate and unusual politically induced injunction process. With provisional measure 744/2016, the EBC adopted a new configuration and extinguished the Curator's Council, an advisory and deliberative body that was constituted as an instrument for the participation of society. It also changed the legal status and mandate of the Director-President, which before the measure could only be removed from office by two votes of mistrust by the Curator's Council.

Edited in partnership by the Communication and Society Research Centre of the University of Minho and the Faculty of Communication of the University of Brasília, this issue contains 13 articles that discuss participation and citizenship, two unavoidable issues when envisaging the role of PSM at a time that is no longer defined by the need to guarantee the minimum but rather by the necessity to build a trustworthy alternative.

In the opening article, Márcia Detoni, shows that in an era marked by multiple platforms for content distribution, oligopolization of the media sectors and transnationalization of cultural industries, the PSM needs to find a new social function that justifies state investments. Based on the thinking of the German philosopher and sociologist Jürgen Habermas, the author puts forward the idea that this new function is precisely the creation and strengthening of a broad public media sphere, capable of guaranteeing citizens a space for debate on collective issues, in a process that stimulates citizen participation and transformative action.

In sequence, Fernando Oliveira Paulino, Liziane Guazina and Madalena Oliveira discuss the concept, contexts and experiences in a comparative approach in Brazil and Portugal, aiming to understand the political, social and cultural framework of the activity of public media in both countries. Departing from the reading of legal documents that support the development of this activity, the authors identify the challenges faced by the national operators. 
In "Law, Society and Communication: an Examination of the Draft Law of the Democratic Media in Brazil", Danilo Rothberg, Carlo José Napolitano and Tatiana Stroppa contextualize the dynamics of social movements for the democratization of the media. The focus of the analysis is the process leading to the proposal of a draft law and to the collection of 1.4 million signatures to force its presentation to Parliament. The popular initiative text, although characterized by relevant innovations, is marked by conceptual inaccuracies and by potentially complex management issues that must face great resistance from hegemonic sectors.

Management challenges for the incorporation of new digital technologies in public broadcasting services in Brazil and Portugal are analyzed by researchers Carlos Eduardo Esch and Mariana Martins de Carvalho. In their article, the authors identify factors that hinder the adherence to new technologies, largely through a type of professional culture that is based on the compartmentalization of functions and which disseminates insecurity and resistance to convergence strategies.

The explanation for these resistances can partly be perceived in Elton Pinheiro's text, "Public radios in Brazil: reflections on their conditions of origin, contemporary setting and challenges". Based on Roger Fidler's (1997) argument that forces of the past shape the future, the author presents the conditions of origin of the brazilian public broadcasting service to identify impasses / obstacles in the face of its necessary (re-) configuration in the information and digital communication environment.

The work of the Curator's Council of the Empresa Brasil de Comunicação (EBC), the main instance of civil society participation in the public service communication company, is the theme of the article by Allana Meirelles Vieira and Iluska Maria da Silva Coutinho. This is an urgent and necessary analysis, which has gained particular relevance following its recent extinction. The paper departs from its short lived history focusing in particular on the different ways of choosing the representatives of civil society and its concrete functioning, namely in the pursuit of its remit to oversee and ensure the public nature of the company.

Sara Pereira, Jairo Faria and Clarisse Pessôa inquire whether Media Literacy is a relevant dimension of PSM based on the analysis of 16 editions of ombudsman / ombudsman programs from the Brazilian and Portuguese public operators (Empresa Brasil de Comunicação - EBC, and Radio e Televisão de Portugal - RTP). The research results indicate that the ombudsman plays an important role as a media literacy agent by actively promoting debates with audiences.

In a context of increasing appreciation for citizen participation in audiovisual public services, Inês Mendes and Raquel Martins reflect on the type of representation citizens really have in media contents. The authors analysed citizen presence in 21 broadcasts of Jornal da Tarde, the main midday news service of the Portuguese PSM operator, RTP. They conclude that although essential to news production as content credibility enhancers, citizens do not yet have a strong presence as sources of information. More often than not, they appear in information spaces because they are voluntarily or involuntarily involved in a certain situation. Citizens' opinions on public space debate structuring issues (such 
as matters of a political nature, issues related to education, health or justice) do not tend to be sought by journalists and presented in these news services.

If the citizen has his voice conditioned to limited spaces in mainstream journalism production, activism and participation in the Internet are indicators of increased relevance in the broader sphere of public debate. Caroline Kraus Luvizotto, in analyzing two Brazilian political and social experiences that stimulate participation, 'Vote on the Web' and 'Participatory Observatory for Youth', however shows that websites also present challenges, namely in terms of architecture, accessibility and usability. They should be enhanced - the author argues - to allow for free conversation among users and thus effectively promote the development of a culture of participation and strengthen existing mechanisms of activism in society, schools, neighborhood associations, civil society organizations and in all governmental instances.

Another interesting aspect of participatory initiatives is the citizen's role in discussing regulatory frameworks. Christine Horz reviews the public discussion process on reforming the regulatory structure of the German public media service in detail. It concludes that the public consultation process created a broader debate on media policies in Germany, a subject previously neglected in terms of both civil society and regulation and communication studies.

This edition also includes a mapping of the musical and cinematographic co-productions on public radio and television in Portugal and in Brazil, by Teresa Costa Alves, Flávia Rocha, Pedro Portela and Dacia Ibiapina. The authors reveal particularities of the cultural industry of the two countries in this multicultural study. Brazil exports much of its musical and cinematographic production to Portugal and the Portuguese public radio has also presented a considerable absorption capacity of Brazilian musical products. In cinema, Portugal has been Brazil's main partner in feature film co-productions and the only lusophone country with which Brazil has a consolidated relationship under the direct promotion policy.

In "The educational radio in the perception of teachers of basic education - The school radio case of the More Education Program", Edgard Patrício deals with public policies of media literacy and communication. It analyzes the perception of public school system teachers of Fortaleza (Brazil) on the use of educational radio in curricular activities. When analyzing interviews with teachers from public schools that joined the project, the author realized that the learning processes are heavily focused on literacy and the approach to media is timid.

Pauline Trouillard looks at the financing of the European Union public broadcasting services, specifically at the ways of controlling public investment so as not to affect competition and the advertising market. It critically addresses proportionality tests carried out by the European Commission to verify whether or not there is excessive compensation or disproportionate effects of public funding. The author concluded that public broadcasters freedom to make available any type of program, as long as it respects the advertising market, has proved to be contrary to the well-being of the citizen.

Going back to a text to which we referred in the beginning, we tend to agree with Karol Jakubowicz when he tells us that there is no guarantee that PSM will survive the 
century in which we live. In any case, "it is, however, certain that it will not survive unless it fundamentally transforms itself. Public service media need to mobilise public support for the institution and their programme of transformation" (Jakubowicz, 2007, p. 45). We trust that these works - some of them because they will also be signs of a very special moment in the history of Brazil and Portugal - are a serious contribution to the debate that needs to be made permanently.

\section{BibLIOGRAPHIC REFERENCES}

d'Haenens, L., Sousa, H. \& Hultén, O. (2011). From public service broadcasting to public service media. In J. Trappel, W. A. Meier, L. d'Haenens, J. Steemers \& B. Thomass, Media in Europe today (pp. 185-218). Bristol/Chicago: Intellect.

Fidler, R. (1997). Mediamorphosis - understanding new media. Thousand Oaks: Pine Forge Press.

Jakubowicz, K. (2007). Public service broadcasting in the 21st century - What chance for a new beginning? In G. F. Lowe \& J. Bardoel (Eds.), From public service broadcasting to public service media (pp. 29-49). Göteborg: Nordicom.

Lowe, G. F., Goodwin, P. \& Yamamoto, N. (2015). Crossing borders and boundaries in PSM - Heritage, complication and development. In G. F. Lowe \& N. Yamamoto (Eds.), Crossing borders and boundaries in public service media (pp. 11-27). Gothenburg: Nordicom. Retrieved from http://www.nordicom.gu.se/ sites/default/files/publikationer-hela-pdf/crossing_borders_and_boundaries_in_public_service_media. pdf.

Lowe, G. F. \& Bardoel, J. (2015). From public service broadcasting to public service media. Gothenburg: Nordicom. Retrieved from http://www.nordicom.gu.se/sites/default/files/publikationer-hela-pdf/ ripe_2007_from_public_service_broadcasting_to_public_service_media.pdf

Mendel, T. (2011). Serviço público de radiodifusão: um estudo de direito comparado. Brasília: Unesco.

Rosen, J. (2006, 27 de junho). The people formerly known as the audience [Post em blogue]. Retrieved from http://archive.pressthink.org/2006/06/27/ppl_frmr.html.

\section{BIOGRAPHIC NOTES}

Luís António Santos is an Auxiliary Professor at the Communication Sciences Department and Deputy-Director of the Communication and Society Research Centre at the University of Minho, Braga, Portugal. His research interests include ongoing changes in Journalism, new formats in sound production, and the political economy of communications in the Lusophone space. He has been a journalist for more than a decade, with professional experiences both in Portugal and abroad in press, radio and TV.

Email: Isantos@ics.uminho.pt

Centro de Estudos de Comunicação e Sociedade - ICS

Universidade do Minho

Campus de Gualtar

4710-057 Braga, Portugal 
Nelia Del Bianco is a Professor at the Communication Post-Graduate Programmes of Universidade de Brasília and Universidade Federal de Goiás. Holding a PhD in Communication from the Communication and Arts School at Universidade de São Paulo (USP) with a post-doctoral internship at Universidade de Sevilha, Spain. Her research interests are centred on Radio and its place in contemporary life and on Public Service Media in Latin America. She has been Vice-President of Sociedade Brasileira de Estudos Interdisciplinares da Comunicação - Intercom - between 2008 and 2011 and its Head of Documentation between 2011 and 2014. Currently Head of International Relations at Federação Brasileira das Associações Científicas e Acadêmicas de Comunicação (Socicom).

E-mail:nbianco@uol.com.br

Programa de Pós-Graduação em Comunicação

Universidade de Brasília

Campus Darcy Ribeiro

70900-910 Brasília, Brasil 